\title{
Influência da corrosão e de tensões cíclicas alternadas na vida em fadiga dos ferros fundidos nodulares das classes FE 50010 e FE 50007
}

\author{
Influence of corrosion and alternating cyclic \\ stresses on fatigue life of FE 50010 and \\ FE 50007 nodular cast irons
}

\footnotetext{
${ }^{1}$ Universidade do Estado de Santa Catarina, Centro de Ciências Tecnológicas, Departamento de Engenharia Mecânica, Campus Universitário, Bairro Zona Industrial Norte, 89219-710, Joinville, SC, Brasil.

${ }^{2}$ Universidade do Estado de Santa Catarina, Centro de Ciências Tecnológicas, Departamento de Engenharia Mecânica, Campus Universitário, Bairro Zona Industrial Norte, 89219-710, Joinville, SC, Brasil. e-mail: crisleide.izauro@gmail.com, enori.gemelli@udesc.br
}

\begin{abstract}
RESUMO
O ferro fundido nodular da classe FE 50007 é amplamente utilizado em aplicações de engenharia, principalmente na indústria automobilística. Contudo, nos últimos anos o ferro fundido nodular da classe FE 50010 está sendo usado cada vez mais em substituição ao ferro fundido nodular da classe FE 50007 por causa de sua maior ductilidade. Esta propriedade confere ao material menor dureza, favorecendo a usinagem e, consequentemente, tendo um menor custo final de produção. Além da dureza, as propriedades mecânicas em tração também apresentam uma pequena diferença entre um material e outro. Contudo, para as aplicações de engenharia com carregamento dinâmico a seleção do material também depende de seu comportamento em fadiga. Sendo assim, o objetivo deste trabalho foi de estudar a vida em fadiga dos dois ferros fundidos nodulares em condições ambientais naturais e após exposição em névoa salina. Antes dos ensaios de fadiga os materiais foram caracterizados por meio de análise química, metalografia, ensaios de dureza e de tração. Os ensaios de fadiga foram realizados por flexão rotativa em condições naturais ambientais e após exposição em névoa salina por 48, 96, 168 e 240 horas. O ferro fundido FE 50007 apresenta maior dureza e resistência mecânica em tração, mas menor ductilidade do que o FE 50010. Estas propriedades estão relacionadas com as fases presentes: o FE 50007 é composto de nódulos de grafita, ferrita e cementita; enquanto o FE 50010 é composto de nódulos de grafita e ferrita. O ferro fundido FE 50010 apresentou maior vida em fadiga para tensões de flexão iguais ou inferiores a $250 \mathrm{MPa}$ em condições ambientais naturais. Após exposição em névoa salina o ferro fundido FE 50010 também apresentou maior resistência em fadiga para tensão de flexão de $250 \mathrm{MPa}$. Os produtos de corrosão são porosos e frágeis, e compostos basicamente por óxidos e hidróxidos de ferro.
\end{abstract}

Palavras-chave: Ferro fundido nodular, Fadiga por flexão rotativa, Névoa salina, Corrosão.

\section{ABSTRACT}

The FE 50007 nodular cast iron is widely used in engineering applications, mainly in the automobile industry. However, in the last years the FE 50007 nodular cast iron is being replaced by the FE 50010 nodular cast iron because of its greater ductility. The ductility leads to a decrease in hardness, favoring the machining and, consequently, having a lower final cost of production. Besides the hardness, tensile mechanical properties also present a small difference between the materials. However, for engineering applications with dynamic loading the selection of the material also depends on its behavior in fatigue. Therefore, the aim of this work was to study the fatigue life of these two nodular cast irons under natural environmental conditions and after salt spray exposition. Before the fatigue tests the materials were characterized by chemical analysis, metallography, hardness and tensile tests. The fatigue tests were performed by rotating bending under natural environmental conditions and after salt spray corrosion for 48, 96, 168 and 240 hours. The FE 50007 cast iron has higher hardness and mechanical strength but less ductility than the FE 50010. These properties are related to 
the present phases: the FE 50007 is composed of graphite nodules, ferrite and cementite, while the FE 50010 is composed of graphite nodules and ferrite. The FE 50010 cast iron presented higher fatigue life for tensile bending equal or less than $250 \mathrm{MPa}$ under natural environmental conditions. After exposure to salt spray, the FE 50010 cast iron also presented higher fatigue strength for a tensile bending of $250 \mathrm{MPa}$. The corrosion products are porous and brittle, and basically composed of iron oxides and hydroxides.

Keywords: Nodular cast iron, Rotating bending fatigue, Salt spray, Corrosion.

\section{INTRODUÇÃO}

Os ferros fundidos nodulares apresentam uma grafita em forma de nódulos e possuem uma grande variação de propriedades. O aspecto mais importante deste material é o micro estrutural que o caracteriza com presença de nódulos de grafita, que agem como bloqueadores de trincas garantindo maior ductilidade e tenacidade quando comparado a outros ferros fundidos. Os nódulos de grafita espalham-se pela matriz e determinam as suas propriedades mecânicas [1].

Cheng et al.[2] destacam que o ferro fundido nodular vem sendo amplamente utilizado em vários setores da indústria automobilística, devido a sua alta resistência a tração, escoamento, excelente fundibilidade e usinabilidade. Além destas propriedades, a resistência a fadiga também é um fator que deve ser avaliado dependendo da aplicação do material. A fadiga trata-se da queda da resistência ou a fratura de um material devido a uma tensão variável no tempo, normalmente inferior ao limite de escoamento, sendo um fenômeno comum nos componentes sujeitos a carregamentos dinâmicos [3]. Uma trinca por fadiga inicia em locais de concentração de tensões após um determinado número de ciclos, sendo sua propagação de natureza frágil. Conforme a trinca se desenvolve, ocorre o aumento de concentração de tensões, resultando no aumento da velocidade de propagação da trinca e por fim sua propagação final ao atingir um tamanho crítico [4,5].

A classe de ferro fundido nodular que apresenta menor custo de fabricação é a FE 50007, por não precisar de uso de elementos de liga especiais, nem tratamento térmico para obter suas propriedades mecânicas [4]. No entanto, outra classe que vem ganhando mercado na indústria automobilista é a FE 50010. Em comparação com a classe convencional, apresenta uma pequena diferença nas suas propriedades mecânicas e microestrutura, mas a principal diferença é o percentual de silício, que favorece a formação de ferrita da matriz. Em relação às características no processo de usinagem, segundo Santos [6], devido à classe FE 50010 possuir menor dureza reflete positivamente em maior vida útil das ferramentas de usinagem, menor emissão de ruídos das ferramentas, aumento da velocidade de avanço e corte de metal, e consequentemente usinam-se mais peças em menor tempo. Desta forma têm-se processos de usinagem com menores custos, devido à redução no consumo de ferramentas, sendo muito positivo e um fator que pode ser o diferencial em produzir um produto com menor custo benefício.

O presente trabalho tem por objetivo investigar a resistência à fadiga das duas classes de ferros fundidos anteriormente citadas, de modo a avaliar se além dos ganhos nas propriedades mecânicas e na usinagem, a vida em fadiga da classe FE 50010 é superior à classe FE 50007, de modo a ser ou não um fator decisivo na seleção do material. Esta comparação será realizada através do ensaio de fadiga por flexão rotativa em corpos de prova em condições ambientais naturais e em condições ambientais agressivas (exposição à névoa salina), análise das propriedades mecânicas e composição química de cada material.

\section{MATERIAIS E MÉTODOS}

Os materiais que foram analisados neste trabalho referem-se aos ferros fundidos nodulares das classes FE 50007 e FE 50010, sendo um perlítico e o outro ferrítico, respectivamente. A partir do ferramental de moldagem, foram fundidos 66 blocos Y de cada liga em estudo, sendo esta realizada na máquina da marca Hunter, modelo HMP-20G, na fundição da empresa Schulz S.A. As dimensões do bloco Y foram embasadas na norma [7] e o vazamento foi realizado na temperatura de $1398^{\circ} \mathrm{C}$.

\subsection{Análise química}

As análises químicas foram realizadas em espectrômetro de emissão óptica da marca SpectroSul, modelo spectrolab através da queima em pequenos discos coquilhados ("moedas") de cada liga (corrida), que são gerados a partir de uma amostra do metal líquido antes de ser efetuado o vazamento. As análises químicas foram realizadas na empresa Schulz S.A.

\subsection{Preparação e análise metalográfica}

As amostras metalográficas foram obtidas através do corte da área útil do bloco Y com serra mecânica. Estas 
foram esmerilhadas no rebolo na região fraturada até obter uma superfície plana. Os cantos vivos e rebarbas também foram removidos. A preparação das amostras para posterior análise metalográfica foi realizada por meio do lixamento com água nas lixas de granulação de 220, 400 e 600, sempre com rotação da amostra de $90^{\circ}$ no lixamento subsequente. Após o lixamento foi realizado o polimento em politriz rotativa utilizando pano de polimento e alumina de $1 \mu \mathrm{m}$ a uma velocidade de $600 \mathrm{rpm}$ até o desaparecimento dos riscos gerados pelo lixamento. As análises metalográficas e quantitativas foram feitas utilizando-se o microscópio óptico da marca Olympus, modelo BX51M e o software Stream Essentialis. A forma da grafita foi determinada de acordo com [8] presentes no software. O grau de nodularização foi obtido através da comparação da imagem obtido do corpo de prova no microscópio a uma ampliação de 100 vezes. Para a revelação da microestrutura (matriz) foi utilizado uma solução de Nital 3\% (Ácido Nítrico 3\% + Etanol 97\%) por aproximadamente 30 segundos. Na sequência o corpo de prova foi lavado com álcool etílico e seco com soprador industrial. A determinação da matriz (percentual de perlita e ferrita) foi realizada utilizando o microscópio a uma ampliação de 100 vezes. A preparação metalográfica foi realizada no Laboratório de Preparação de Amostras da empresa Schulz S.A.

\subsection{Ensaio de dureza Brinell}

Foram realizados ensaios de dureza Brinell em 05 amostras de cada liga. Em cada amostra foi realizado um ensaio. Os testes de dureza foram processados conforme [9]. Os ensaios foram realizados em um durômetro do fabricante Izda, modelo 207FD, com penetrador esférico de $5 \mathrm{~mm}$ de diâmetro e carga de $750 \mathrm{kgf}$, onde a determinação do diâmetro de impressão foi realizada com o auxílio do software CDB Brinell, através da leitura automática e controle da dureza Brinell com sistema de captura. A medição da dureza foi realizada na empresa Schulz S.A.

\subsection{Ensaio de tração}

Os ensaios de tração foram realizados à temperatura ambiente (ao ar), segundo [10,11] em uma máquina universal de ensaios da marca Wolpert, modelo 20TUZ745 de $200 \mathrm{kN}$ de capacidade. Os corpos de prova foram preparados com base em [7] (corpo de prova com $14 \mathrm{~mm}$ de diâmetro). Através deste ensaio foram determinados os valores do limite de resistência a tração, limite de escoamento e alongamento total. Os resultados foram obtidos por meio do software de ensaios PANTEC acoplado a máquina de ensaios. Foram ensaiados 05 corpos de prova para cada uma das ligas em estudo. O ensaio foi realizado na empresa Schulz S.A

\subsection{Ensaio de fadiga}

Para realização do ensaio de fadiga por flexão rotativa foram cortadas 35 amostras dos blocos Y de cada material com serra mecânica. Após o corte, foram usinados 35 corpos de prova de cada liga em torno CNC, sendo estes confeccionados com base em [12]. A Figura 1 mostra as dimensões do corpo de prova e a Figura 2 mostra uma imagem do corpo de prova usinado.

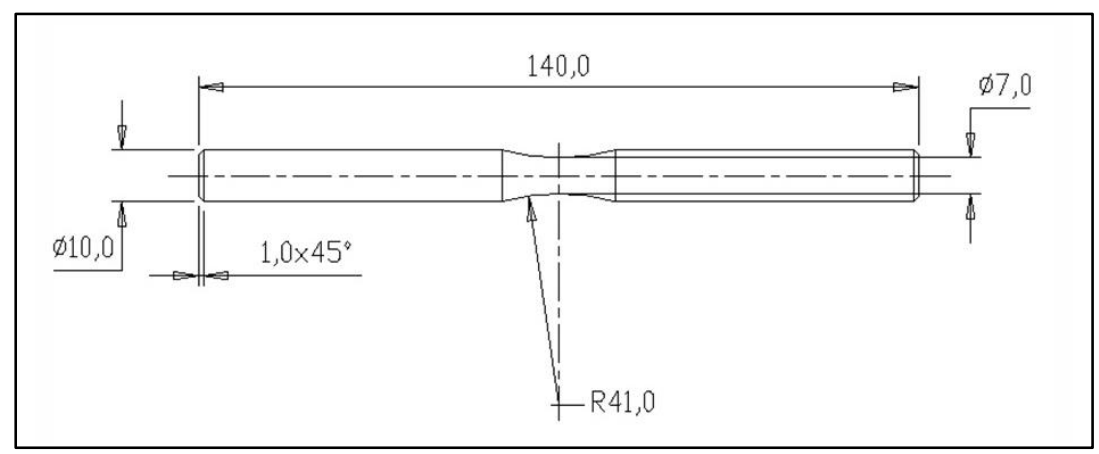

Figura 1: Dimensões do corpo de prova para ensaio de fadiga. 


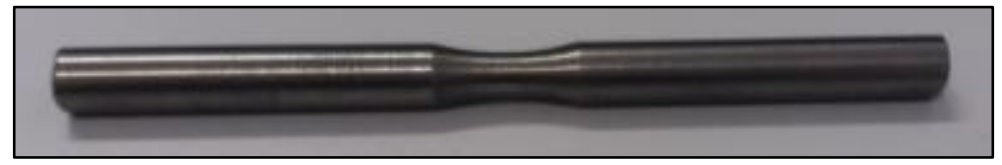

Figura 2: Corpo de prova usinado (FE 50010).

Após a usinagem, os corpos de prova foram limpos com álcool etílico. Posteriormente foi medido o diâmetro da região de teste (útil) com paquímetro digital da marca Mitutoyo $(0-200 \mathrm{~mm})$ e a rugosidade com rugosímetro da marca Mahr, modelo PS1-6910210. A preparação dos corpos de prova foi realizada na empresa Schulz S.A. Os ensaios de fadiga foram realizados em temperatura ambiente na máquina de fadiga por flexão rotativa TYP RM 506 do laboratório de ensaios mecânicos (UDESC/CCT).

Foram ensaiados 5 corpos de prova para cada tensão de flexão nos ensaios realizados em condições ambientais naturais. Os corpos de prova foram ensaiados até romper ou até 107 ciclos, tendo em vista que o limite de fadiga dos ferros fundidos é da ordem de 106 ciclos. As tensões de flexão foram calculadas conforme a Equação 1.

$$
\sigma=\frac{156960}{\pi} \frac{\mathrm{P}}{\mathrm{d}^{3}}(\mathrm{MPa})
$$

Onde d (mm), o diâmetro útil do corpo de prova, medido no centro do corpo de prova; e P (kgf) a carga aplicada na ponta do braço da alavanca da máquina.

\subsection{Ensaio de corrosão em câmara salt spray}

O método de ensaio por exposição à névoa salina foi realizado na câmara de salt spray (aparelho para testes de corrosão no qual a máquina é preparada para simular uma condição em que o material é exposto a uma condição mais agressiva que acelera o processo de corrosão) marca Bass e modelo USC-MP-01 utilizando como base em [13,14]. A solução de ensaio foi preparada com água destilada contendo $5 \%$ de cloreto de sódio $(\mathrm{NaCl}) . \mathrm{O}$ pH da solução foi ajustado para a faixa de 6,5 a 7,2 conforme instruções das normas. A pressão de ar comprimido foi mantida entre $0,7 \mathrm{e} 1,4 \mathrm{Kgf} / \mathrm{cm}^{2}$. A zona de exposição da câmara de ensaio manteve-se a uma temperatura de aproximadamente $35^{\circ} \mathrm{C}$. Neste ensaio foram utilizados 12 corpos de prova de cada liga para os ensaios de fadiga, sendo três amostras de cada material para cada ciclo de exposição: 48, 96,168 e 240 horas conforme demostrado na Tabela 1.

Tabela 1: Relação dos corpos de prova versus ciclo de exposição à nevoa salina.

\begin{tabular}{ccccc}
\hline \multirow{2}{*}{ Material } & \multicolumn{4}{c}{ Tempo de Exposição (horas) } \\
\cline { 2 - 5 } & 48 & 96 & 168 & 240 \\
\hline FE 50007 & $\mathrm{A}-\mathrm{B}-\mathrm{C}$ & $\mathrm{D}-\mathrm{E}-\mathrm{F}$ & $\mathrm{G}-\mathrm{H}-\mathrm{I}$ & $\mathrm{J}-\mathrm{L}-\mathrm{M}$ \\
\hline FE 50010 & $\mathrm{N}-\mathrm{O}-\mathrm{P}$ & $\mathrm{Q}-\mathrm{R}-\mathrm{S}$ & $\mathrm{T}-\mathrm{U}-\mathrm{V}$ & $\mathrm{W}-\mathrm{X}-\mathrm{Y}$ \\
\hline
\end{tabular}

Os corpos de prova foram limpos com álcool etílico e o diâmetro da região de teste (útil) foi medido com paquímetro digital da marca Mitutoyo $(0-200 \mathrm{~mm})$. Posteriormente os corpos de prova foram dispostos horizontalmente na câmara de salt spray de modo que os mesmos não se tocassem durante o ensaio conforme mostra a Figura 3. Os ensaios foram realizados na empresa Schulz S.A. 


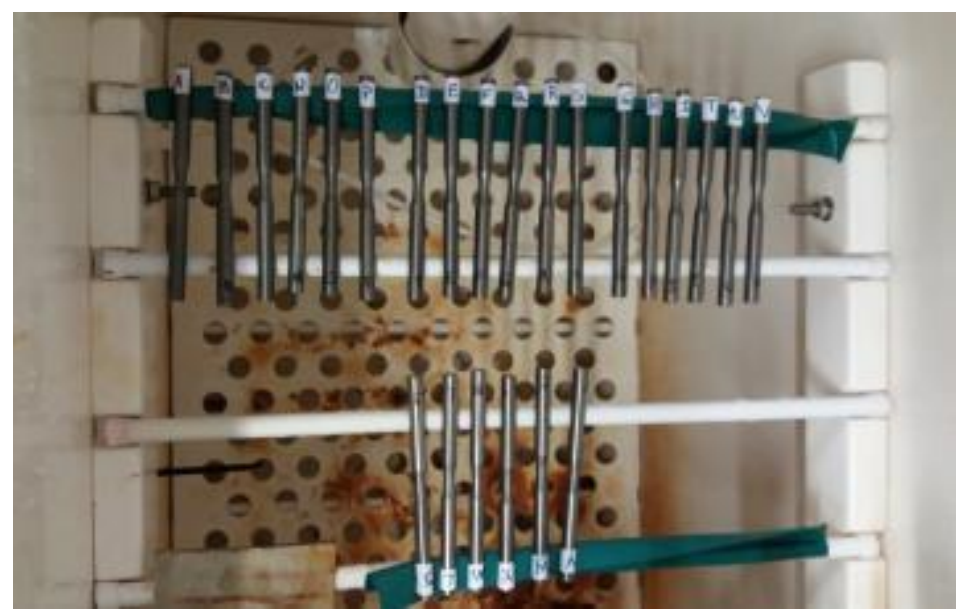

Figura 3: Disposição dos corpos de prova na câmara de salt spray.

Após a conclusão do ciclo de cada ensaio, os corpos de prova foram removidos da câmara, lavados com água destilada para eliminar os depósitos de sal da superfície, secos com secador e armazenados em sacos VCI para posterior ensaio de fadiga por flexão rotativa. Utilizaram-se os sacos VCI (inibidor volátil de corrosão) de modo a evitar que os corpos de prova continuassem no processo de oxidação. Para estes corpos de prova os ensaios de fadiga foram realizados com tensão de flexão de $250 \mathrm{MPa}$.

\subsection{Microscopia eletrônica de varredura (MEV)}

As análises de superfície dos corpos de prova fraturados por fadiga foram realizadas por microscopia eletrônica de varredura (MEV), com efeito de campo (Field Emission Gun - FEG) marca Jeol, modelo JSM-6701F (UDESC/CCT). As amostras foram obtidas através do corte transversal com serra manual da ponta dos corpos de prova fraturados, a base do corpo de prova foi lixada com lixa de granulação 100 para deixar a superfície plana e remover as rebarbas oriundas da serra manual. Para avaliação da superfície fraturada das amostras foi utilizado um corpo de prova rompido de cada tensão oriundo do ensaio de fadiga em temperatura ambiente. Nos corpos de prova submetidos à névoa salina foi realizada a verificação em uma amostra de cada liga com 96 h de exposição para verificar se as trincas iniciam nos pontos de corrosão.

\section{RESULTADOS E DISCUSSÕES}

\subsection{Análise química}

A composição química resultante das duas ligas em estudo está apresentada na Tabela 2, sendo que estas foram analisadas de modo a avaliar se os resultados obtidos estavam de acordo com as especificações. Pode-se observar que os valores encontrados na análise química estão de acordo com [15].

Tabela 2: Resultado da composição química das ligas de ferro fundido nodular FE 50007 e FE 50010.

\begin{tabular}{ccccc}
\hline \multirow{2}{*}{$\begin{array}{c}\text { Elemento } \\
\text { massa }\end{array}$} & \multicolumn{2}{c}{ Ferro 50007 } & \multicolumn{2}{c}{ FE 50010 } \\
\cline { 2 - 5 } & $\begin{array}{c}\text { Norma } \\
\text { ISO 1083/2004 }\end{array}$ & Encontrado & $\begin{array}{c}\text { Norma } \\
\text { ISO } 1083 / 2004\end{array}$ & Encontrado \\
\hline $\mathbf{C}$ & $3,2-4,0$ & 3,58 & 3,3 & 3,32 \\
\hline $\mathbf{S i}$ & $1,5-2,8$ & 2,2 & 3,7 & 3,72 \\
\hline $\mathbf{M n}$ & $0,05-1,0$ & 0,299 & Máx. 0,3 & 0,202 \\
\hline $\mathbf{P}$ & Máx. 0,08 & 0,041 & Máx.0,05 & 0,0338 \\
\hline $\mathbf{S}$ & Máx. 0,02 & 0,011 & Máx. 0,02 & 0,0086 \\
\hline $\mathbf{M g}$ & $0,03-0,08$ & 0,038 & 0,04 & 0,042 \\
\hline $\mathbf{C u}$ & $0-0,5$ & 0,023 & Máx. 0,1 & 0,019 \\
\hline $\mathbf{C e q}$ & - & 4,33 & - & 4,576 \\
\hline $\mathbf{M o}$ & - & 0,002 & - & 0,0005 \\
\hline $\mathbf{N i}$ & - & 0,012 & - & 0,0188 \\
\hline
\end{tabular}


Através da análise comparativa dos materiais, observou-se que o elemento que apresenta uma diferença significativa de concentração entre as duas ligas é o silício. O acréscimo da concentração de silício na liga causa formação de maiores percentagens de ferrita na matriz metálica devido à elevação do número de nódulos por $\mathrm{mm}^{2}$, diminuindo a dureza, os limites de resistência à tração e de escoamento e elevando o alongamento [16].

\subsection{Análise metalográfica}

Na Figura 4 são apresentados os resultados da caracterização micro estrutural da liga FE 50007. A Figura 4(a), sem ataque, foi utilizada para determinar o número de nódulos de grafita (pontos pretos) e a Figura 4(b), com ataque de solução de nital 3\%, revelou uma matriz perlítica-ferrítica com $70 \%$ de perlita e $30 \%$ de ferrita. As partes pretas mostradas nas imagens são nódulos de grafita e a região clara em torno dos nódulos de grafita é a ferrita. As demais regiões são da perlita, que é constituída de lamelas de cementita (escura) e lamelas de ferrita (branca). A formação de perlita está diretamente relacionada a adição dos elementos de liga $\mathrm{Sn}, \mathrm{Cu}$ e Mn.

A liga apresentou uma distribuição normal de grafitas esferoidais e um número de nódulos por $\mathrm{mm}^{2}$ de aproximadamente 305. O grau de nodularização foi $80 \%$, sendo a grafita nas formas V-VI e o tamanho variou de 3 a 6 conforme [8].

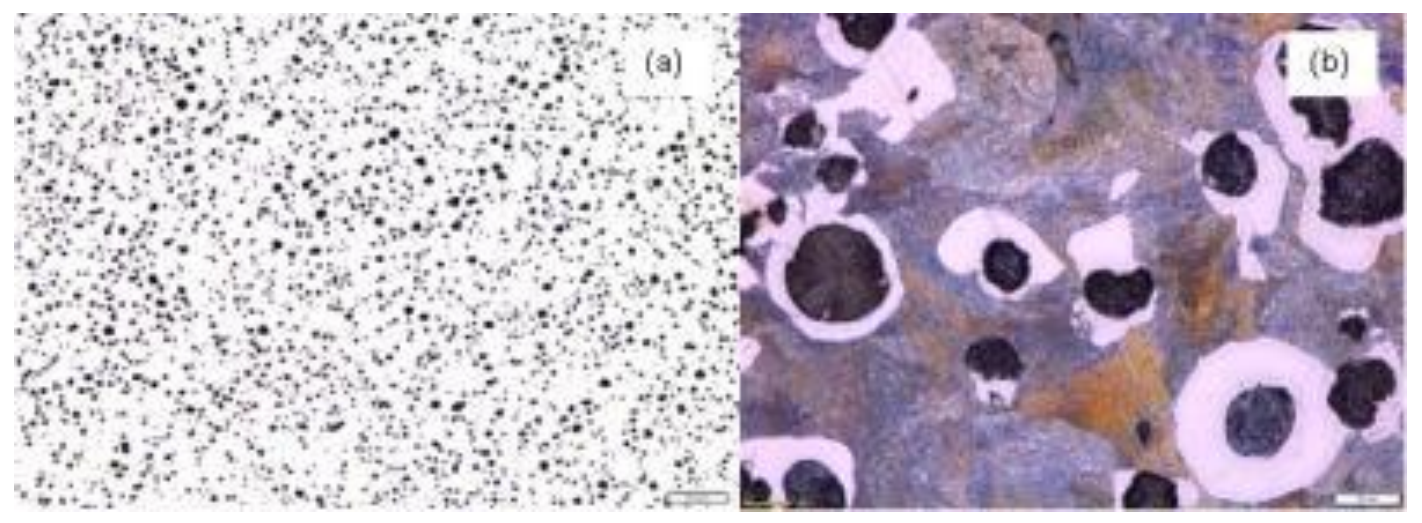

Figura 4: Microestrutura da liga FE 50007 revelada por microscopia óptica: sem ataque (a) ampliação 100X, com ataque nital 3\% (b) ampliação 500X.

A Figura 5 apresenta a microestrutura da liga FE 50010, na qual a matriz revelou-se $100 \%$ ferrítica, apresentando uma distribuição normal de grafitas esferoidais com aproximadamente 398 nódulos de grafita por $\mathrm{mm}^{2}$. A grafita corresponde aos pontos pretos sobre as figuras. $\mathrm{O}$ grau de nodularização encontrado variou de 90 a 100\%, sendo a grafita nas formas V-VI e o tamanho variou de 6 a 7 conforme [8].

A ausência de perlita na liga FE 50010 está relacionada com o teor de silício, que tem por efeito inibir a formação de perlita na liga [4].

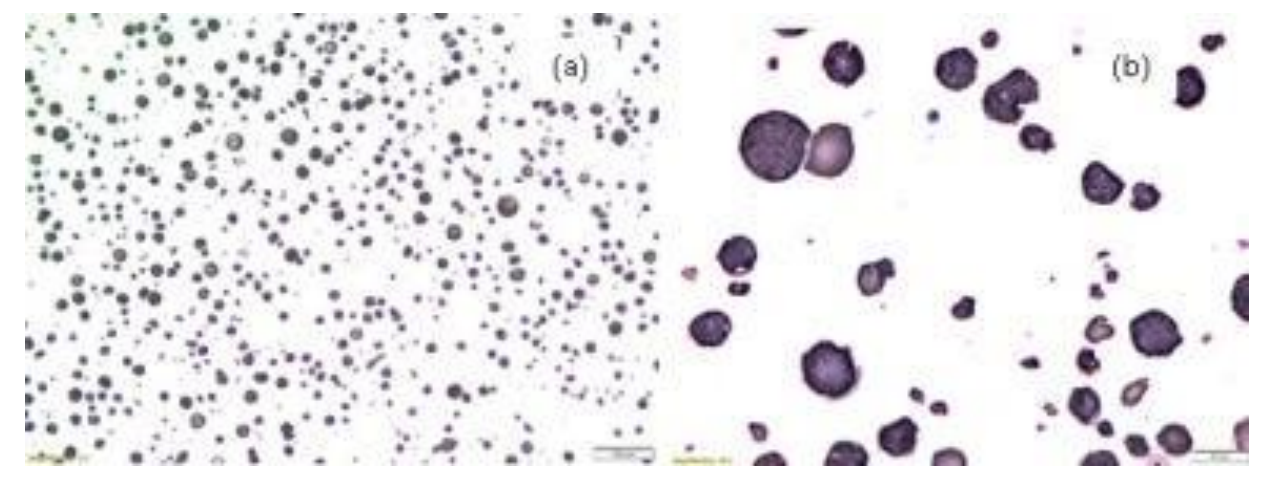

Figura 5: Microestrutura da liga FE 50010 revelada por microscopia óptica: sem ataque (a) ampliação 100X, com ataque nital 3\% (b) ampliação 500X. 
A distribuição da grafita foi normal em ambas às ligas em estudo, sendo sua forma um fator preponderante na determinação das características mecânicas do ferro fundido nodular. A forma da grafita está diretamente relacionada ao elevado número de nódulos esféricos que implica em menor probabilidade de ocorrência de grafita de forma degenerada na microestrutura [17]. As partículas de grafitas degeneradas (com contornos irregulares) aumentam a concentração de tensão, reduzindo a resistência a fadiga e ao impacto [18].

Observou-se também que o número de nódulos foi superior no FE 50010, sendo que este fator afeta o tamanho e a forma da grafita. Segundo [17], a elevação do número de nódulos resulta na diminuição do tamanho do nódulo que melhora a resistência à tração, fadiga e propriedades de fratura. As práticas de inoculação (que se refere a adição de uma liga metálica enquanto o metal ainda está na fase líquida) melhoram frequentemente a quantidade do número de nódulos e os tornam mais esféricos. Desta forma, um elevado número de nódulos é geralmente associado com uma melhora na nodularidade.

Os difratogramas de raios-X (DRX) dos ferros fundidos FE 50007 e FE 50010, mostrados na Figura 6, apresentaram picos de elevada e baixa intensidade do ferro para ambas as ligas em estudo, e picos de média intensidade de grafita/cementita $\left(\mathrm{Fe}_{3} \mathrm{C}\right)$ para $\mathrm{FE} 50007$ e grafita para o FE 50010. Estes confirmam as fases observadas anteriormente na metalografia.

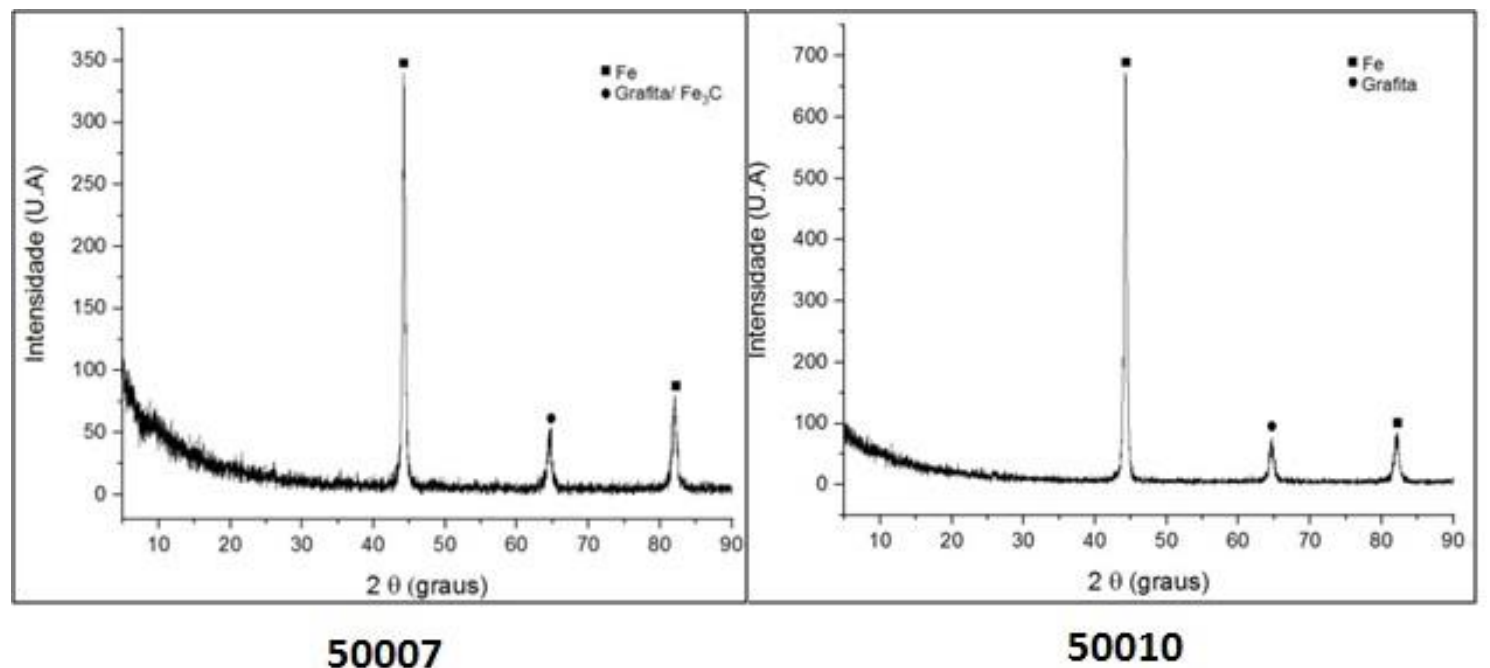

Figura 6: Difratograma de raios-X do ferro fundido FE 50007 e 50010.

\subsection{Ensaios de dureza e tração}

Os resultados de dureza Brinell obtidos nos dois ferros fundidos encontram-se na Tabela 3. No ferro fundido nodular FE 50007 os valores de dureza ficaram dentro do estabelecido pela [15], mas mais próximos do limite superior que é de $230 \mathrm{kgf} / \mathrm{mm}^{2}$, resultando em um valor médio de $220,6 \mathrm{kgf} / \mathrm{mm}^{2}$. No ferro fundido nodular FE 50010 os valores de dureza também ficaram dentro do estabelecido pela norma, mas com valores intermediários entre os limites inferior e superior, tendo um valor médio de $198,6 \mathrm{kgf} / \mathrm{mm}^{2}$. Portanto, o ferro fundido nodular FE 50010 apresenta uma dureza média inferior ao ferro fundido nodular FE 50007.

Tabela 3: Resultados da dureza Brinell $\left(\mathrm{kgf} / \mathrm{mm}^{2}\right)$

\begin{tabular}{ccc}
\hline Corpo de prova & FE 50007 & FE 50010 \\
\hline Norma ISO 1083/2004 & $170-230$ & $185-215$ \\
\hline $\mathbf{1}$ & 229 & 205 \\
\hline $\mathbf{2}$ & 209 & 206 \\
\hline $\mathbf{3}$ & 216 & 192 \\
\hline $\mathbf{4}$ & 229 & 197 \\
\hline $\mathbf{5}$ & 220 & 193 \\
\hline Média \pm DP & $220,6 \pm 7,7$ & $198,6 \pm 5,9$ \\
\hline
\end{tabular}

Para cada material foram realizados 5 ensaios de tração sendo que as curvas de tração de cada material ficaram muito semelhantes. Para cada curva de tração foram retiradas a tensão de escoamento e a tensão de 
ruptura. $\mathrm{O}$ alongamento plástico foi determinado por meio de medidas no corpo de prova. Estes resultados encontram-se nas Tabelas 4 e 5 . A tensão de escoamento foi determinada para uma deformação de $0,2 \%$, valor comumente usado na indústria metalúrgica para estes materiais.

Tabela 4: Resultados das propriedades mecânicas obtidas em tração no ferro fundido nodular FE 50007

\begin{tabular}{cccc}
\hline Corpo de prova & $\begin{array}{c}\text { Tensão de escoamento } \\
\text { (MPa) }\end{array}$ & $\begin{array}{c}\text { Tensão de Ruptura } \\
\text { (MPa) }\end{array}$ & $\begin{array}{c}\text { Alongamento } \\
\text { (\%) }\end{array}$ \\
\hline Norma ISO 1083/2004 & mín. 320 & mín. 500 & mín. 7 \\
\hline $\mathbf{1}$ & 403,03 & 672,50 & 7,78 \\
\hline $\mathbf{2}$ & 395,62 & 658,50 & 7,21 \\
\hline $\mathbf{3}$ & 397,51 & 650,00 & 7,42 \\
\hline $\mathbf{4}$ & 423,65 & 689,90 & 6,51 \\
\hline $\mathbf{5}$ & 408,26 & 669,60 & 7,59 \\
\hline Média \pm DP & $405,61 \pm 10,04$ & $668,10 \pm 13,54$ & $7,30 \pm 0,44$ \\
\hline
\end{tabular}

Tabela 5: Resultados das propriedades mecânicas obtidas em tração no ferro fundido nodular FE 50010

\begin{tabular}{cccc}
\hline Corpo de prova & $\begin{array}{c}\text { Tensão de escoamento } \\
\text { (MPa) }\end{array}$ & $\begin{array}{c}\text { Tensão de Ruptura } \\
(\mathbf{M P a})\end{array}$ & $\begin{array}{c}\text { Alongamento } \\
\mathbf{( \% )}\end{array}$ \\
\hline Norma ISO 1083/2004 & mín. 360 & mín. 500 & 10 \\
\hline $\mathbf{1}$ & 438,25 & 541,00 & 15,28 \\
\hline $\mathbf{2}$ & 427,94 & 538,00 & 15,45 \\
\hline $\mathbf{3}$ & 437,71 & 540,00 & 14,50 \\
\hline $\mathbf{4}$ & 438,34 & 539,60 & 12,38 \\
\hline $\mathbf{5}$ & 428,48 & 539,60 & 12,77 \\
\hline Média \pm DP & $434,14 \pm 4,85$ & $539,64 \pm 0,96$ & $14,08 \pm 1,27$
\end{tabular}

Os dois materiais apresentam propriedades mecânicas próximas, sendo que a maior diferença está na tensão de ruptura e no percentual de alongamento plástico. O limite de resistência (tensão de ruptura) está de acordo com a dureza, ou seja, quanto maior a dureza, maior o limite de resistência. Por isso, o ferro fundido FE 50007 apresentou maior limite de resistência em tração do que o ferro fundido FE 50010.

Quanto ao alongamento plástico também houve uma diferença significativa entre os dois materiais. No ferro fundido FE 50007 o alongamento plástico médio foi de 7,30\% enquanto que no ferro fundido FE 50010 ele foi de 14,08\%. Esta característica confere ao FE 50010 maior ductilidade quando comparado ao FE 50007, que está diretamente relacionado ao aumento de porcentagem de silício na liga. O silício causa uma redução progressiva no limite de resistência à tração para teores de 1,87 a 3,14\% (de silício). Em contrapartida o alongamento aumenta conforme a quantidade de silício é maior [19].

\subsection{Ensaios de fadiga}

Os resultados dos ensaios de fadiga das duas ligas estão apresentados de forma gráfica nas Figuras 7 e 8 . É a representação de Wöhler, que para o caso de flexão rotativa, relaciona a tensão máxima em função do número de ciclos. No caso dos ferros fundidos aqui estudados tanto o eixo da tensão quanto o do número de ciclos estão em escala logarítmica.

Foram realizados cinco ensaios para cada tensão aplicada, com exceção das tensões aplicadas próximas do limite de fadiga onde o número de ensaios dependeu da necessidade de variação da tensão aplicada para determinação do limite de fadiga dos materiais. Os corpos de prova utilizados nos ensaios de fadiga tinham acabamento de superfície usinado. Eles foram ensaiados nesta condição para simular as condições de serviço dos materiais. 


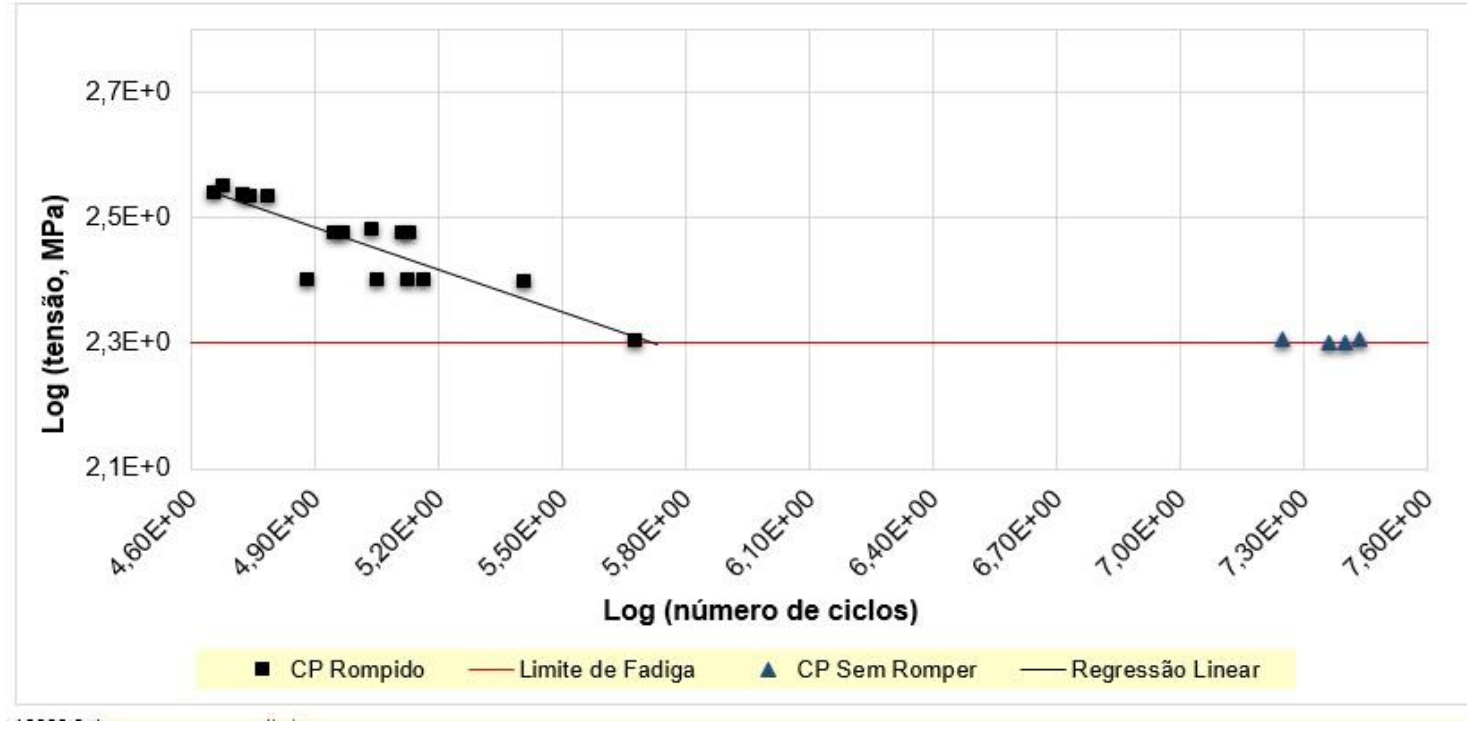

Figura 7: Curva de Wöhler do ferro fundido FE 50007

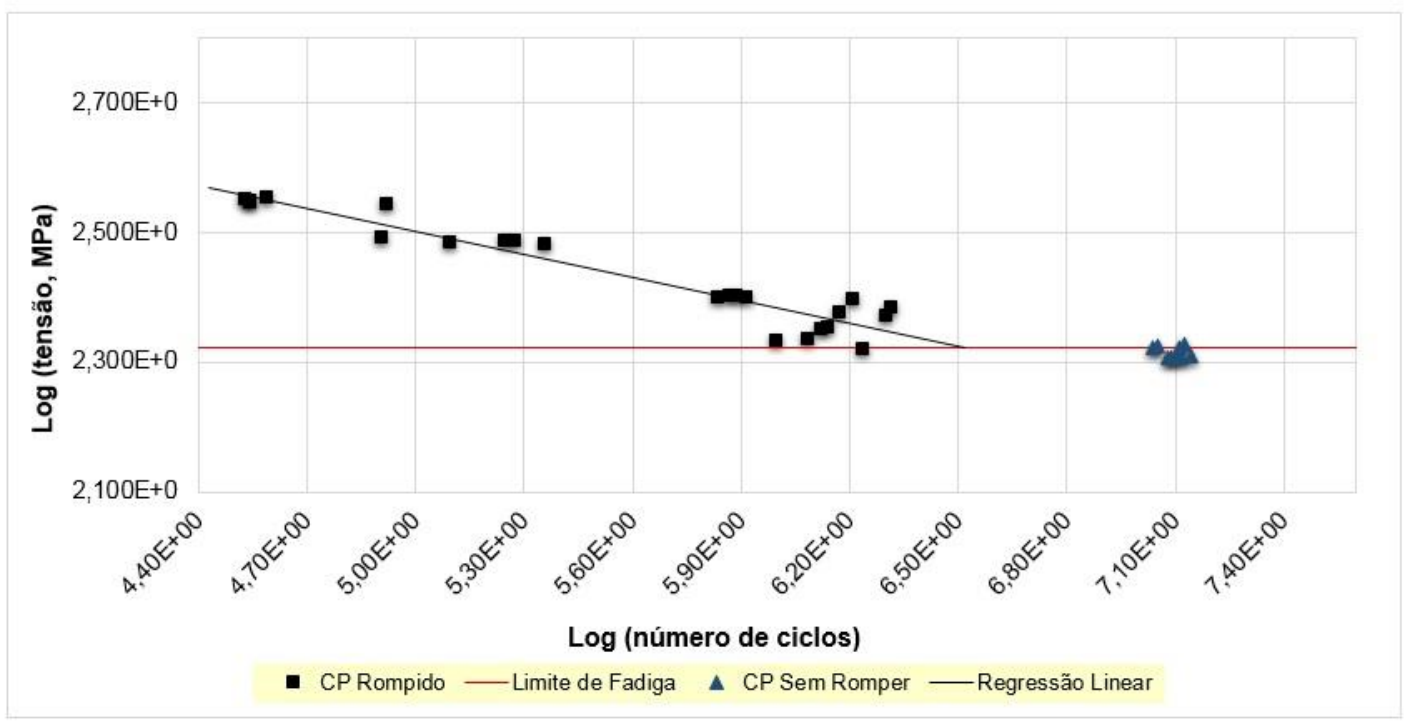

Figura 8: Curva de Wöhler do ferro fundido FE 50010

Pode-se observar nas Figuras 7 e 8 que houve uma dispersão significativa dos valores experimentais, que é uma característica dos ensaios de fadiga. A linha de tendência dos pontos experimentais dos corpos de prova rompidos é linear na representação log-log, em ambos os materiais. O limite de fadiga do ferro fundido FE 50007 foi de log da tensão igual a 2,31 MPa, que corresponde a $200 \mathrm{MPa}$. Para o ferro fundido FE 50010 o limite de fadiga encontrado foi de $210 \mathrm{MPa}$.

A Figura 9 mostra os resultados de fadiga dos dois materiais para comparação. Para valores de tensão mais elevados não há diferença significativa entre os dois materiais. Á medida que a tensão aplicada diminui (maiores números de ciclos), observa-se uma diferença progressiva na vida em fadiga. Para tensões iguais ou inferiores a $250 \mathrm{MPa}$ a diferença na vida em fadiga é significativa entre os dois materiais.

Embora o ferro fundido FE 50010 apresente maior vida em fadiga a baixos ciclos do que o ferro fundido Fe 50007, os limites de fadiga entre os dois materiais ficaram próximos. 


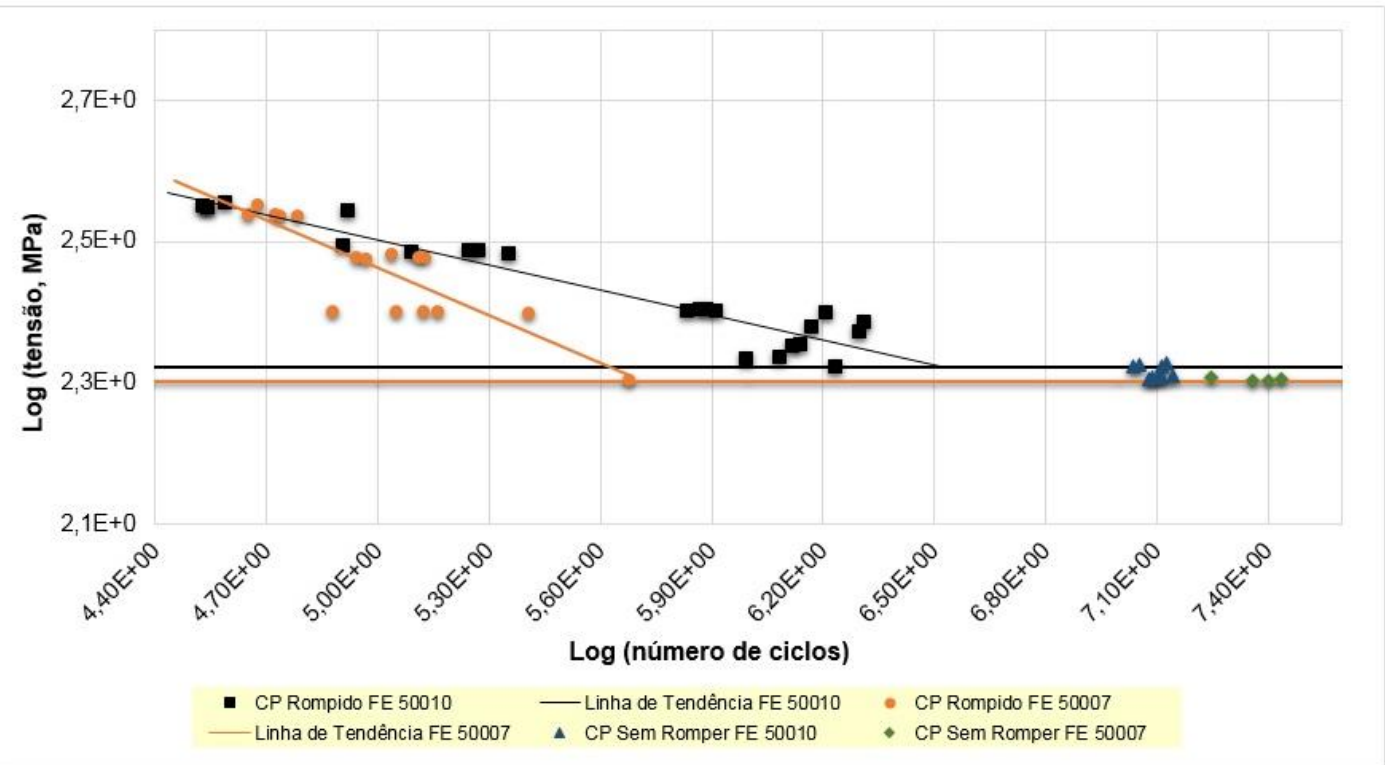

Figura 9: Comparação das Curvas de Wöhler entre o FE 50007 e o FE 50010

O limite de fadiga do ferro fundido FE 50007 corresponde a 0,40 vezes a tensão de ruptura em tração do material. Para o ferro fundido Fe 50010 o limite de fadiga corresponde a 0,42 vezes a tensão de ruptura em tração do material. Estes limites estão dentro dos especificados por [20], no qual cita que a relação de limite à fadiga com a resistência a tração das classes ferríticas e perlíticas são semelhantes, reduzindo para 0,5 a 0,4 com aumento crescente da resistência a tração para cada classe.

\subsection{Ensaios de corrosão em câmara de névoa salina}

A Figura 10 mostra o aspecto da superfície das amostras corroídas na câmara de névoa salina após 48, 96, 168 e 240 horas. As amostras apresentaram corrosão generalizada, mas ela não foi uniforme em profundidade, apresentando pequenas cavidades distribuídas aleatoriamente na superfície das amostras em ambos os materiais. A coloração avermelhada nos produtos de corrosão indica a oxidação predominante do ferro.
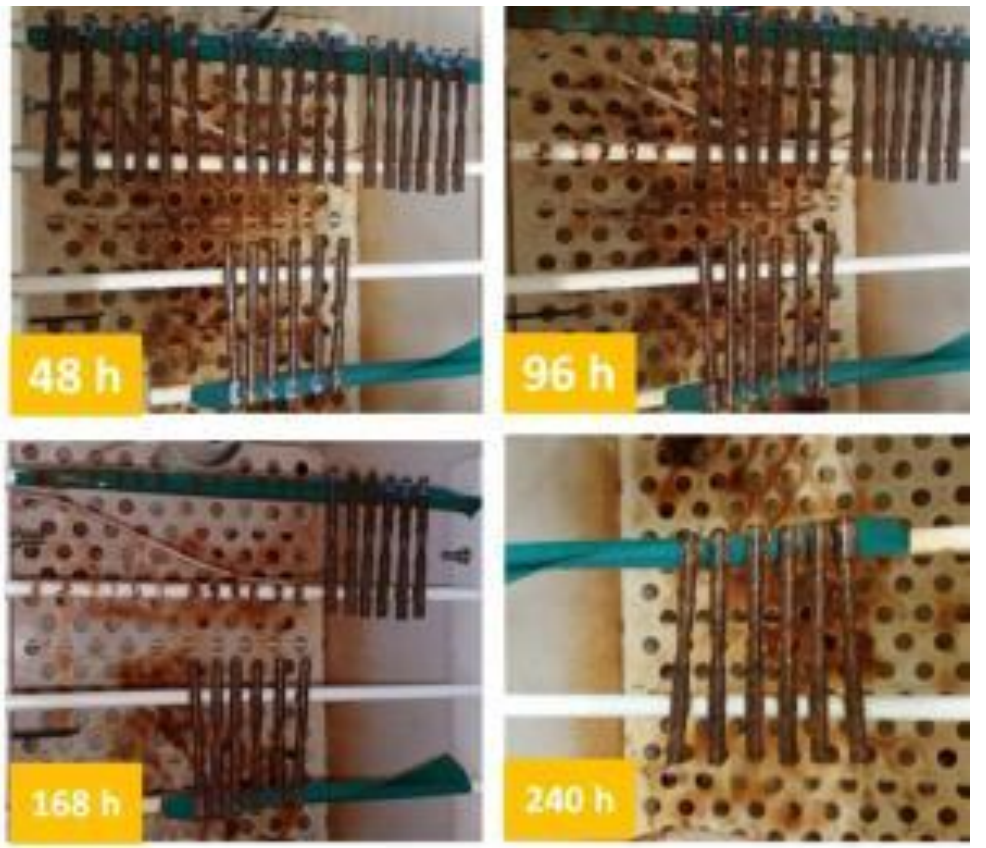

Figura 10: Corpos de prova na câmara de névoa salina 
Após a exposição à névoa salina, os corpos de prova foram submetidos ao ensaio de fadiga por flexão rotativa. Foi medido o número de ciclos em função do tempo de exposição para uma tensão de flexão de 250 $\mathrm{MPa}$. Os resultados dos ensaios encontram-se nas Figuras 11 e 12. Pode-se observar que a resistência em fadiga diminui exponencialmente com o tempo para os dois materiais. A diminuição da vida em fadiga é devido ao aumento da corrosão com o tempo de exposição. A corrosão consome metal em profundidade diminuindo o diâmetro das amostras. Além da diminuição do diâmetro, as cavidades formadas resultam em pontos de concentração de tensão que também aumentam com a profundidade das cavidades.

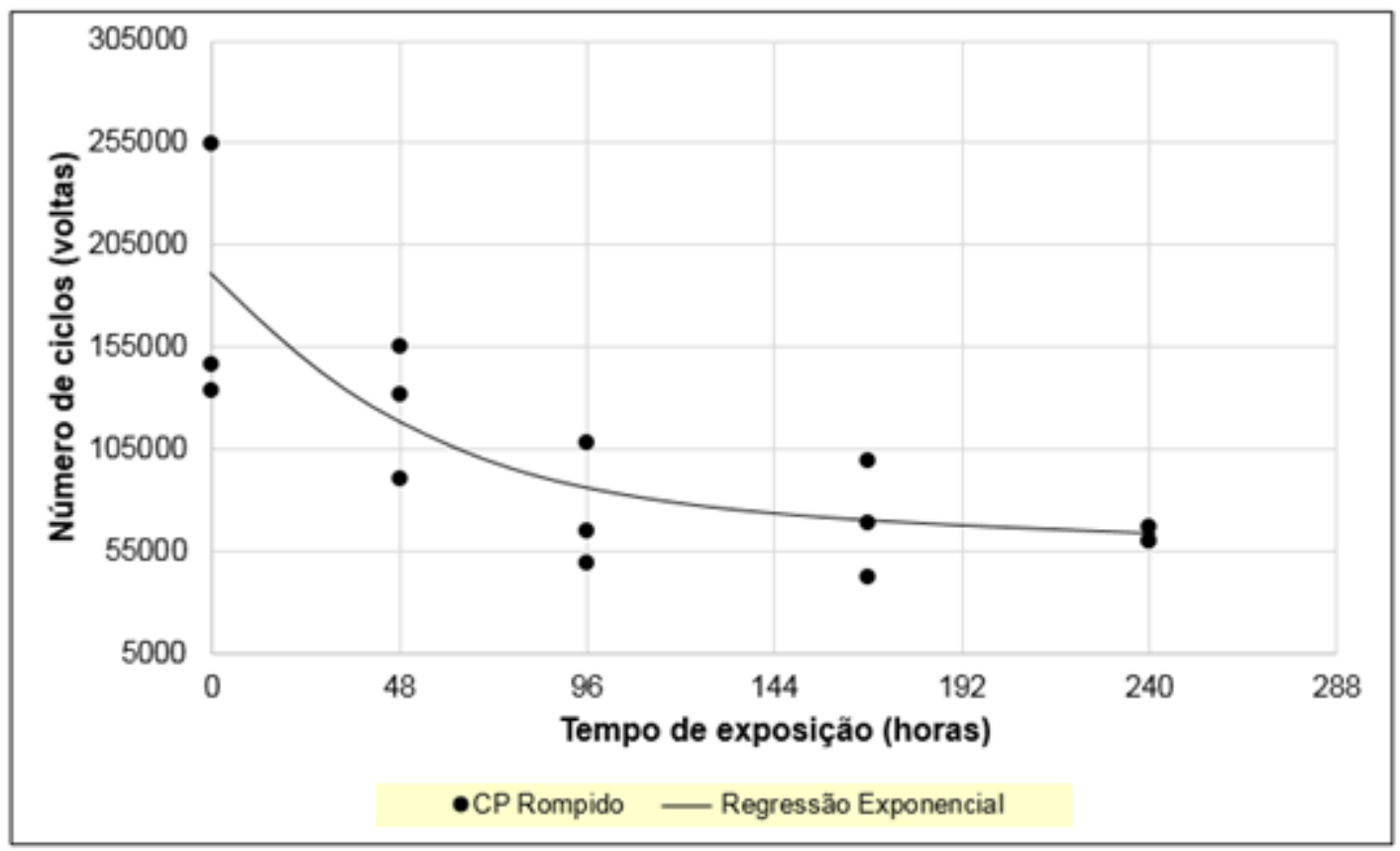

Figura 11: Vida em fadiga do FE 50007 em função do tempo de exposição na câmara de névoa salina para uma tensão de $250 \mathrm{MPa}$

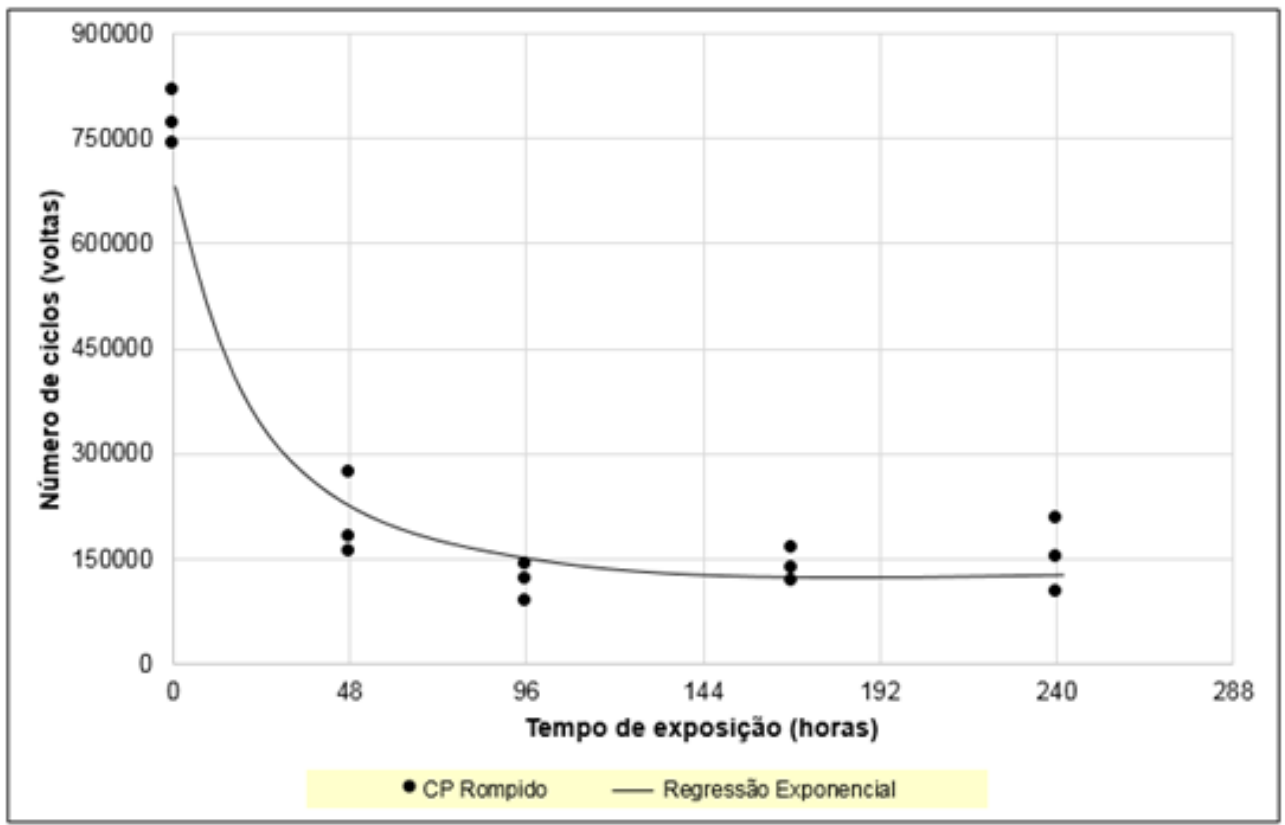

Figura 12: Vida em fadiga do FE 50010 em função do tempo de exposição na câmara de névoa salina para uma tensão de $250 \mathrm{Mpa}$

A Figura 13 mostra o comportamento em fadiga dos dois materiais após a exposição em névoa salina. 
Pode-se observar que o ferro fundido FE 50010 tem maior vida em fadiga do que o FE 50007. Para a tensão de $250 \mathrm{MPa}$ já foi mostrado na Figura 13 que mesmo antes da exposição em névoa salina o ferro fundido FE 50010 apresenta maior vida em fadiga do que o FE 50007. Isso significa que a diferença observada após a exposição em névoa salina não é devido a maior resistência a corrosão do FE 50010. Provavelmente a maior vida em fadiga deste material está relacionada com a maior ductilidade e/ou com a diferença de nodularização entre os dois materiais, fazendo com que o Ferro fundido FE 50010 tenha maior tenacidade.

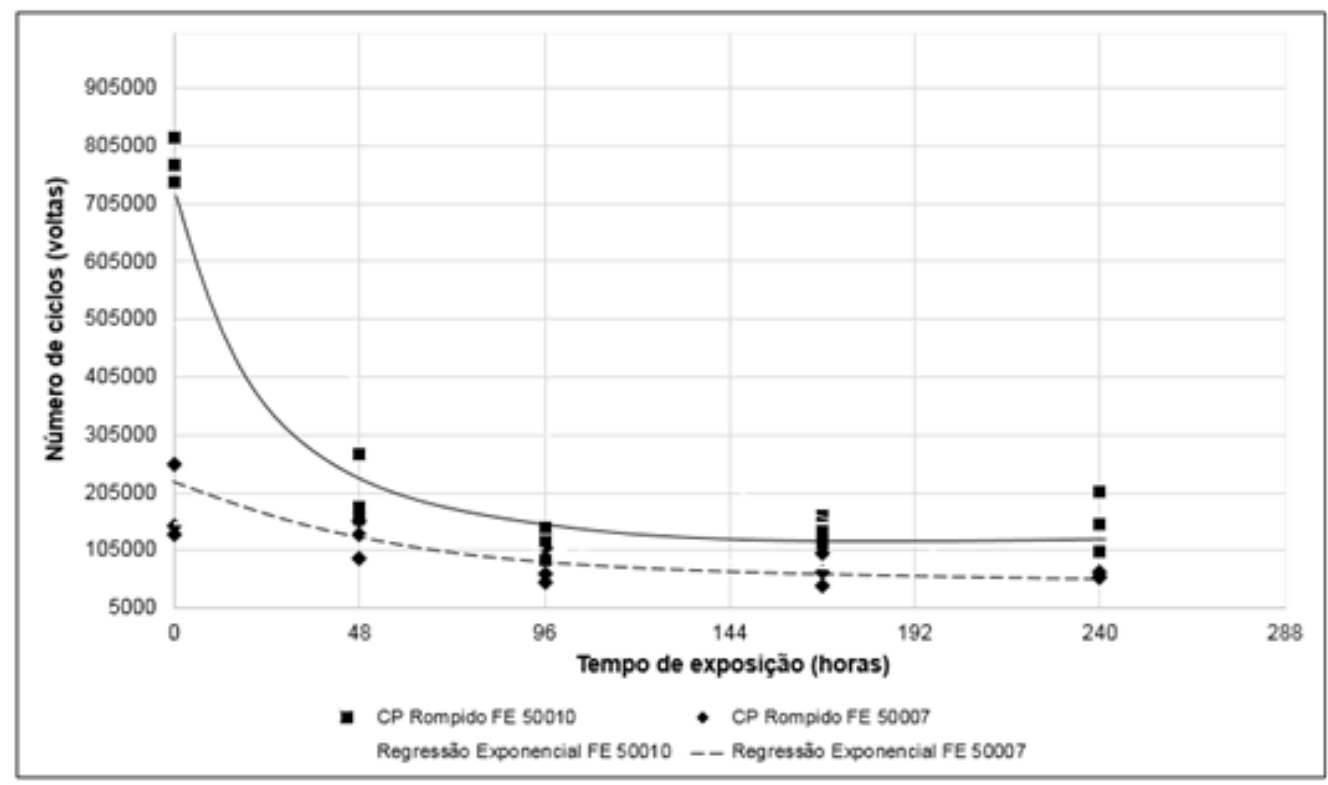

Figura 13: Comparação da vida em fadiga dos dois materiais em função do tempo de exposição na câmara de névoa salina para uma tensão de $250 \mathrm{Mpa}$

\subsection{Caracterização por microscopia eletrônica de varredura (MEV)}

Após os ensaios de fadiga foram analisadas as faces de ruptura de pelo menos uma amostra para cada tensão aplicada. O principal objetivo das análises por MEV foi de identificar os locais de início e propagação das fissuras para verificar se havia relação com as fases presentes nos materiais.

As análises MEV mostraram indícios de que a nucleação das fissuras ocorre na grafita ou na interface entre a grafita e a matriz metálica. A Figura 14 mostra imagens da superfície das duas ligas onde foi observada a presença de fissuras. As cavidades ou as partes arredondadas escuras observadas na face de ruptura são dos vazios deixados pela grafita ou da grafita que fica em uma das partes rompidas do material por fadiga. Pode-se observar na Figura 14 que as fissuras iniciam e se propagam na matriz nos locais onde há grafita ou na interface entre a matriz e a grafita. 

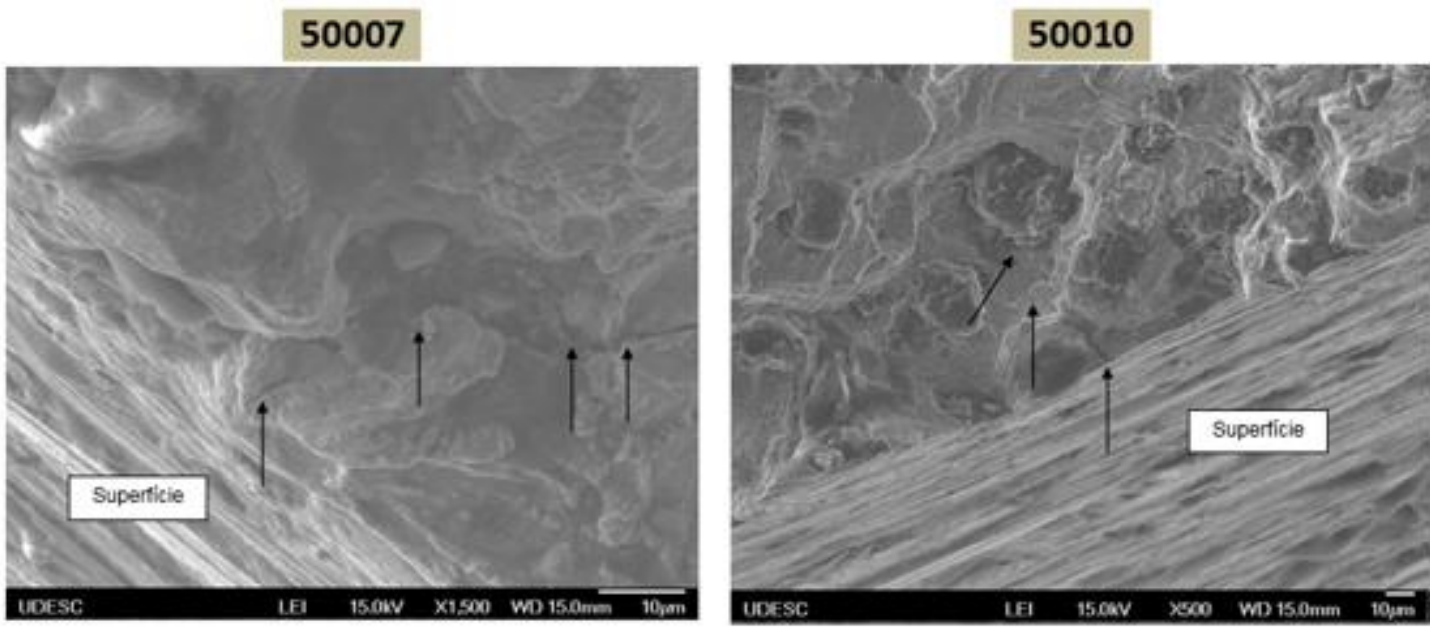

Figura 14: Imagem MEV da face de ruptura de uma amostra do ferro fundido FE 50007 e uma amostra do ferro fundido 50010 mostrando fissuras na superfície

A Figura 15 mostra a face de ruptura da parte final da fratura do corpo de prova, quando a fissura atinge o comprimento crítico e a parte não fraturada rompe instantaneamente. Esta parte apresenta fratura mista frágil/dúctil. A ferrita é dúctil, mas devido a fratura repentina, a ruptura também ocorre por clivagem.

Outra constatação importante é a ruptura dos materiais nos locais da grafita. Pode-se observar que ocorre decoesão na interface grafita/matriz em ambos os materiais. Portanto, a grafita e, principalmente a interface, tem influência nas propriedades mecânicas dos materiais.

\section{7}

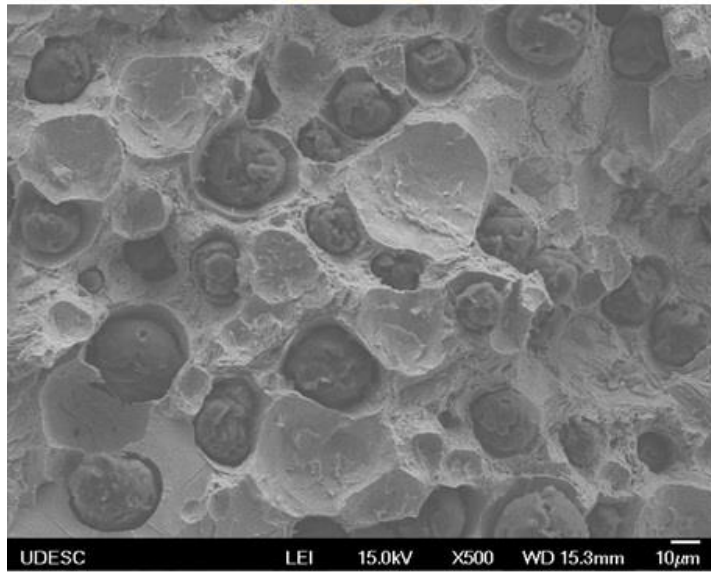

\section{0}

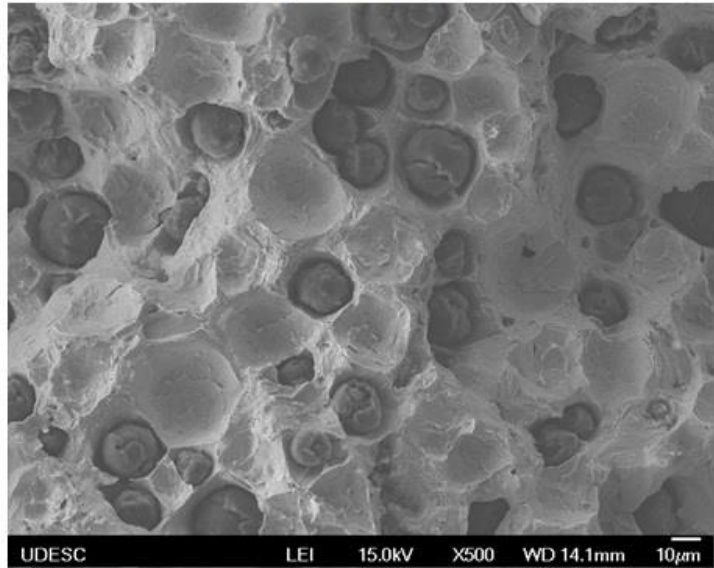

Figura 15: Imagem MEV da face de ruptura da parte fraturada repentinamente no ensaio de fadiga de uma amostra do ferro fundido FE 50007 e uma amostra do ferro fundido 50010

Conforme [4], a fratura por fadiga de ferros fundidos apresenta determinadas características, no qual em nodulares predominantemente ferríticos, verifica-se a predominância de micro cizalhamentos na superfície da fratura enquanto nos nodulares perlíticos a presença de estrias de fadiga é evidente. Ainda de acordo com o autor, as trincas de fadiga propagam-se de nódulo em nódulo, sendo importante a distância entre esses nódulos de grafita. Na passagem por cada nódulo de grafita a trinca pode ocorrer por separação de interface grafita/matriz (em nódulos brutos de fundição), ou então por fratura de grafita no nódulo (em nodulares ferritizados em tratamento térmico), geralmente entre a grafita formada na solidificação e a depositada em tratamento térmico.

Além da análise de amostras fraturadas por fadiga em condições ambientais naturais, também foram analisadas amostras fraturadas por fadiga após os ensaios de névoa salina. A Figura 16 mostra uma imagem 
representativa da nucleação de trincas por fadiga observadas nestas amostras. As trincas se formam nas regiões mais atacadas onde foram observadas camadas espessas de produtos de corrosão. Pode-se observar na Figura 16 que a camada de corrosão não é compacta favorecendo o ataque quando exposta em meio corrosivo.

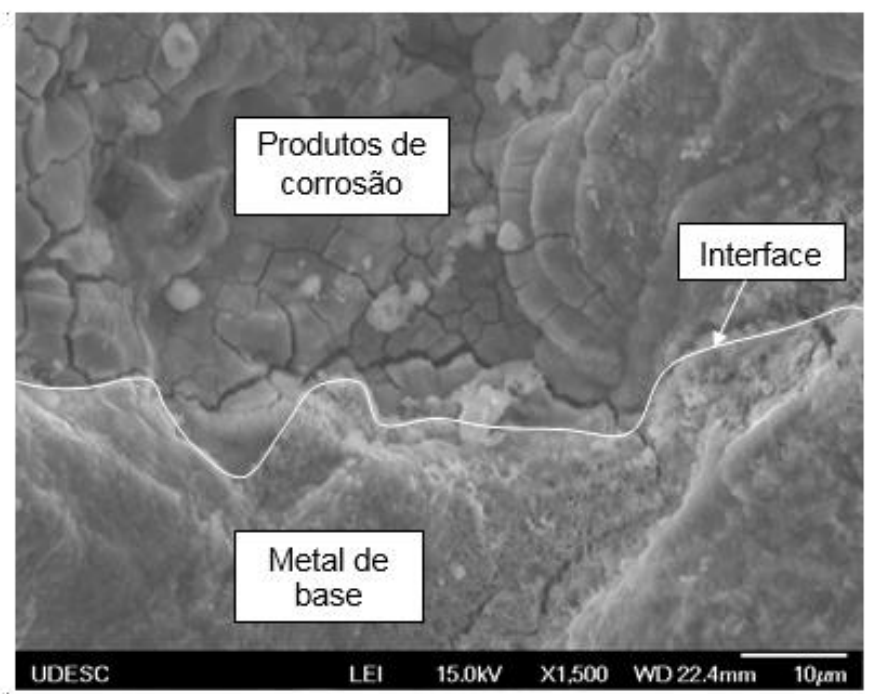

Figura 16: Imagem MEV da face de ruptura de uma amostra do ferro fundido FE 50010 mostrando fissuração do material no fundo da camada de corrosão formada após 96 h de névoa salina.

\subsection{Caracterização físico química dos produtos de corrosão}

Após exposição em névoa salina foi realizada análise química de superfície por espectroscopia de fotoelétrons por raios-X (XPS) e análise física por difração de raios-X (DRX) para identificar os produtos de corrosão.

A Figura 17 mostra os espectros representativos da análise geral por XPS do ferro fundido nodular FE 50007 e FE 50010, respectivamente. Os dois espectros são muito parecidos, sendo que foram identificados os picos dos principais elementos que podem estar na camada de corrosão que são o ferro, oxigênio, silício, cloro e carbono. Tendo em vista o aspecto avermelhado da camada de corrosão, típico de produtos de corrosão de ferro, e que o ferro e o oxigênio foram os elementos com maior concentração encontrados nas análises XPS, foi realizada uma deconvolução do pico do ferro e do oxigênio dos espectros dos dois materiais para verificar o grau de oxidação destes elementos.
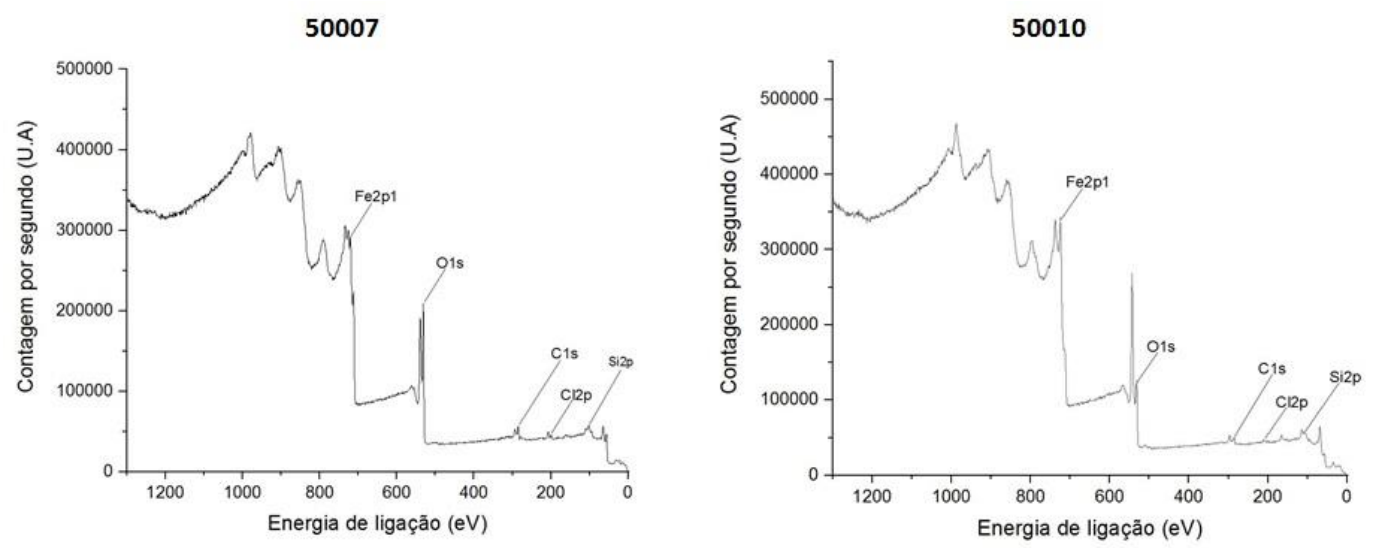

Figura 17: Análise geral por XPS do FE 50007 e FE 50010 após exposição em névoa salina por 96 h. 
Pode-se observar que nos dois materiais o ferro se encontra na camada de corrosão com grau de oxidação $2+$ e $3+$. Sabe-se que em contato com meio aquoso o ferro se oxida formando hidróxido ferroso (ferro $2+$ ), que em presença de oxigênio se transforma em hidróxido férrico (Fe 3+) e/ou em oxihidróxido de ferro (Fe $3+$ ), que podem se amorfos ou cristalinos. Em meio aquoso, também é comum a presença da magnetita (Fe 2+ e Fe 3+) [21].

Nas análises por DRX dos materiais oxidados foi observado que os principais picos coincidem com picos de fases presentes nos materiais não oxidados (Figura 18). Estes picos foram identificados como sendo de $\mathrm{Fe}(\mathrm{OH})_{3}(00-022-0346)$ e $\mathrm{Fe}_{3} \mathrm{O}_{4}$. Somente dois picos não coincidem com aqueles dos materiais não oxidados. Estes picos estão em aproximadamente $2 \theta$ igual a 26 e 35 graus. Eles foram identificados como sendo de $\mathrm{Fe}_{3} \mathrm{O}_{4}$ de acordo com a ficha JPDS 00-028-0491.

Outros elementos que podem fazer parte da camada de corrosão são o carbono, o cloro e o silício. O carbono identificado na análise XPS pode ser de contaminação ou do carbono presente no material na forma de grafita ou cementita. A concentração atômica de carbono encontrada foi de $22 \%$ e de $11 \%$ no ferro fundido FE 50007 e FE 50010, respectivamente. A maior concentração de carbono na camada de corrosão do ferro fundido FE 50007 sugere que parte do carbono é proveniente da corrosão da matriz que contém a fase cementita. A grafita é um material inerte e tende a permanecer intacta. $\mathrm{O}$ carbono presente na camada de corrosão do ferro encontra-se na forma de carbonato, incorporado nos compostos básicos de ferro [21].
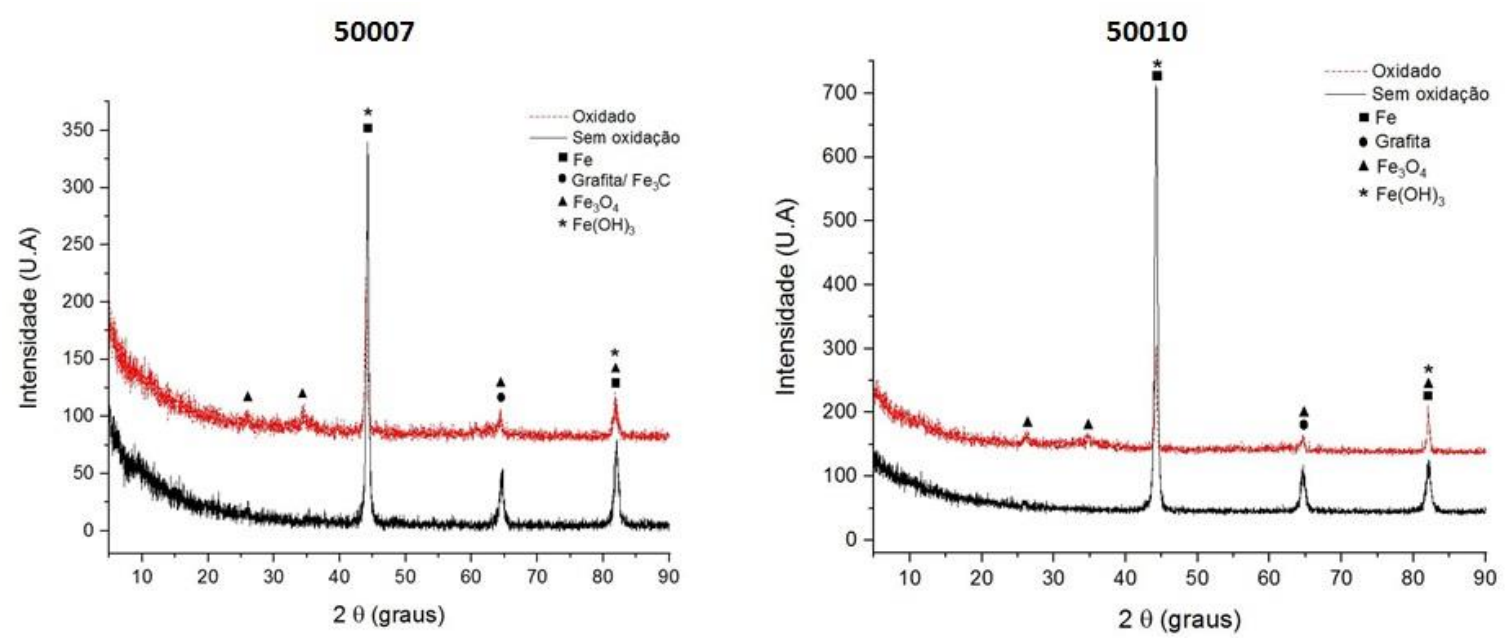

Figura 18: Difratograma de raios-X do ferro fundido FE 50007 e 50010

A concentração de cloro encontrada por XPS foi de 1,2\% (\% atômica) nos dois ferros fundidos. Embora tenha sido encontrada em baixa concentração, a presença deste elemento na camada de corrosão já era esperada, tendo em vista que o meio corrosivo usado foi uma solução aquosa de cloreto de sódio. Neste tipo de meio o cloreto tende a ficar incorporado nos produtos básicos de ferro [21].

A concentração de silício encontrada por XPS foi praticamente a mesma na camada de corrosão dos dois materiais, em torno de 8-9\% (\% atômica). O silício é um elemento reativo e tende a se oxidar em meio corrosivo. Tendo em vista que o silício não forma solução sólida com produtos de corrosão de ferro, ele tende a formar compostos tais como $\mathrm{SiO}_{2}$ e/ou $\mathrm{Fe}_{2} \mathrm{SiO}_{4}$. Devido à baixa concentração de silício nas duas ligas ele tende a formar compostos não contínuos na interface entre a liga e a camada de corrosão. Tendo em vista que a concentração encontrada de silício foi praticamente à mesma nos dois materiais corroídos não é possível saber se a diferença de concentração de silício entre as duas ligas teve alguma diferença no comportamento a corrosão.

\section{CONCLUSÕES}

Neste trabalho foi possível observar que a diferença básica de composição entre os dois ferros fundidos está na maior concentração em silício no ferro fundido FE 50010. O silício tem influência nas fases formadas e nas propriedades mecânicas dos materiais estudados. A presença de silício em maior concentração no ferro fundido FE 50010 inibe a formação de cementita e aumenta o grau de nodularização da grafita. Isto leva a um aumento da ductilidade e diminuição da dureza do ferro fundido FE 50010 quando comparado com o ferro fundido FE 50007. Por consequência, o ferro fundido FE 50010 apresenta valores mais baixos de limite de 
resistência em tração do que o ferro fundido FE 50007.

O ferro fundido FE 50010 apresentou maior vida em fadiga do que o ferro fundido FE 50007 para valores de tensão iguais ou inferiores a $250 \mathrm{MPa}$ em condições ambientais naturais (ao ar). Após névoa salina a vida em fadiga dos dois materiais diminui exponencialmente com o tempo de exposição devido ao ataque corrosivo progressivo. O ferro fundido FE 50010 também apresentou maior resistência em fadiga do que o FE 50007 após exposição em névoa salina para uma tensão de $250 \mathrm{MPa}$.

As análises microfractográficas mostraram fratura típica por clivagem da matriz e que as fissuras iniciam na matriz nos locais onde há grafita ou na interface entre a matriz e a grafita.

As análises por DRX e XPS mostraram que os principais produtos de corrosão formados durante a exposição em névoa salina eram constituídos de óxidos e hidróxidos de ferro. Na inspeção visual pôde-se observar que os produtos de corrosão eram porosos e frágeis.

\section{BIBLIOGRAFIA}

[1] DUARTE, R. I. Noções Básicas de Fundição para Colaboradores em Atividade. 1 ed., Joinville, SOCIESC, 2007.

[2] CHENG, X., et al. "Improvement in corrosion resistance of a nodular cast iron surface modified by plasma beam treatment", Surface Science. v. 286, pp. 334 -343, 2013.

[3] ASKELAND, D. R., PHULÉ, P. P. Ciência e Engenharia dos Materiais. 1 ed., São Paulo, Cengage Learning, 2008.

[4] GUESSER, W. Propriedades Mecânicas dos Ferros Fundidos. São Paulo, Blucher, 2009.

[5] GOODRICH, G. M. Iron Castings Engineering Handbook. AFS, 2003.

[6] SANTOS, D. "Análise comparativa da usinagem de um ferro fundido nodular Alto silício classe FE 50010 em relação a um ferro fundido nodular convencional classe FE 50007”, Dissertação de M.Sc., (UEPG), Joinville, SC, Brasil, 2012.

[7] ANÔNIMO (2012), DIN EN 1563. Founding - Spheroidal graphite cast irons. Technical Committee CEN/TC 190, Alemanha.

[8] ANÔNIMO (2017), ISO 945-1. Microstructure of cast irons - Part 1: Graphite classification by visual analysis. 2 ed. International Organization for Standardization, 2017.

[9] ANÔNIMO (2018), ASTM E10. Standard test method for brinell hardness of Metallic Materials. ASTM International, West Conshohocken, PA, 2018.

[10] ANÔNIMO (2016), ASTM E8M. Standard test methods for tension testing of metallic materials. ASTM International, West Conshohocken, PA, 2016.

[11] ANÔNIMO (2012), NBR ISO 6892. Materiais metálicos-ensaio de tração à temperatura ambiente. Associação brasileira de normas técnicas, 2002.

[12] ANÔNIMO (1996), ATSM E 466-96. Standard practice for conducting force controlled constant amplitude axial fatigue tests of metallic materials. ASTM International, West Conshohocken, PA, 1996.

[13] ANÔNIMO (1983), NBR 8094. Material metálico revestido e não-revestido - corrosão por exposição à névoa salina. ABNT, 1983.

[14] ANÔNIMO (2003), ASTM B117-03. Standard practice for operating salt spray (fog) apparatus. 1ed., ASTM International, West Conshohocken, PA, 2003.

[15] ANÔNIMO (2004), NBR ISO 1083. Spheroidal grafite cast iron - Classification. Associação brasileira de normas técnicas, 2004.

[16] MULLINS, J.D. Nodule count - why and how! Ductile Iron News, n.2, pp.1-2, 2003.

[17] SILVA, C. "Influência do número de nódulos de grafita nas propriedades mecânicas do Ferro fundido nodular austemperado", Dissertação de M.Sc., UFMG, Belo Horizonte, MG, Brasil, 2005.

[18] TRUDEL, A., GAGNÉ, M. "Effect of Composition and Heat Treatment Parameters on the Characteristics of Austempered Ductile Irons", Canadian Metallurgical Quarterly, v.36, n.5, p.289-298, 1997.

[19] MATTAR JÚNIOR, A. R. "Influência dos Elementos de Liga Cu-Ni-Mo nas Propriedades Mecânicas e na Austemperabilidade do ADI”, Dissertação de mestrado (UFSC), São Carlos, SP, 2009. 
[20] MARTINS, R. R. R. "Comparação das propriedades mecânicas e de fadiga entre ferro fundido vermicular e cinzento utilizados em blocos de motor diesel”, Dissertação de mestrado (UFRGS), Porto Alegre, RS, 2012.

[21] BALDEA, G. E., SETEL, A., SEBESAN, M., et al. "Corrosion studies in atmospheric environment", In: Mechanical and Building Industry Days, Urban Energy Conference, Debrecen, Hungary, 13-14 October 2011.

\section{ORCID}

Crisleide Graciema Izauro da Silva

https://orcid.org/0000-0002-4391-4844

Enori Gemelli

https://orcid.org/0000-0003-0881-4562 